\title{
THYROID MALIGNANCY IN MULTI NODULAR GOITER;
}

\author{
INCIDENCE, A RETROSPECTIVE STUDY IN SOUTHERN PUNJAB.
}

Dr. Kashif Nadeem, Dr. Naveed Akhtar, Dr. Javed Mirdad Tarar.

ABSTRACT.....Objectives: To assess the incidence of malignancy in patients with Multinodular goiter in southern Punjab. Study design: A retrospective study. Place \& Duration of study: Department of General Surgery, Sheikh Zayed Medical College \& Hospital Rahim Yar Khan, from April 2010 to May 2012. Patients and Methods: All patients were presented in OPD with history of Multinodular goiter on clinical examination or USG neck. FNAC of any dominant nodule or suspicious nodule on USG neck was performed. All patients were operated \& total thyroidectomies were done in all patients irrespective of the age. We sent all specimens for histopathological examination and reports were collected from department. The whole information collected was entered in a pre designed proforma. Results: During 2 years period, total 141 patients of thyroid disease were seen in OPD out of which 98 patients have Multinodular goiter. Histopathology of these patients showed 10 malignancies \& 88 benign. Most of the patients that turned out to be malignant belong to $41-50$ years age group. 7 patients were female and 3 were male. Among the malignancies $50 \%$ were papillary, $30 \%$ were follicular, and $10 \%$ were anaplastic carcinoma \& lymphomas each. Conclusions: Multinodular goiter (MNG) is the commonest indication of thyroidectomy in iodine deficient areas of Pakistan. This study concludes that don't consider MNG as a benign disease anymore until proved otherwise.

Key words: Thyroid carcinoma, Multinodular goiter, papillary carcinoma.

Article Citation

Nadeem K, Akhtar N, Tarar JM. Thyroid malignancy in multi nodular goiter; incidence, a retrospective study in southern punjab. Professional Med J 2013;20(4):587-590.

\section{INTRODUCTION}

Thyroid carcinoma represents total $1 \%$ of human neoplasm with increasing incidence for the last 4 decades. However, that increase appears to be due to an increase in the diagnosis of papillary microcarcinomas associated with increased sampling of resected specimens by pathologists ${ }^{1}$. Epidemiologically ascertained risk factors are ionising radiation, the presence of thyroid adenoma and multinodular goiter (MNG). Multinodularity of goiter should no longer be considered an indicator of probable benign disease ${ }^{2}$. Traditionally it was thought that multi nodular goiter (MNG) is a benign disease but recently it has been discovered that thyroid malignancy can occur even in MNG.

Review of literature showed no statistical difference in incidence of malignancy in both MNG and solitary nodular goiter ${ }^{3,4}$ and incidence of carcinoma in patients with MNG varies from $7-17 \%$, . The risk of thyroid malignancy in the nodules of MNG is comparable to that which exists in solitary thyroid nodules, the possibility of thyroid malignancy should be considered in all patients with $\mathrm{MNG}^{7}$. FNAB used in solitary nodular goiter as diagnostic tool is not feasible in MNG.

\section{MATERIALS \& METHODS}

This retrospective study has been conducted from April 2010 to May 2012 at Sheikh Zayed Medical College/ Hospital Rahim Yar Khan. We recruited all OPD patients presented with Multinodular goiter on clinical examination or on ultrasound of neck. Preoperatively FNAB of any dominant nodule or nodule which was suspicious on USG neck was performed. Serum level of TSH, FT3, and FT4 was detected to know the toxic status of patient. Scintigraphy was not done because of its low specificity in detection of carcinoma. All the patients included in study were operated and total thyroidectomies were done \& specimens sent for histopathological examinations. With collaboration of histopathological department all reports were collected and all the information was documented on pre-designed proforma.

\section{RESULTS}

In this retrospective study of two years total 141 
patients were operated for thyroid lesions, out of which 98 patients were with multi nodular goiter. Total thyroidectomy was done in 76 patients, but in 22 patients subtotal thyroidectomy was done. Total 21 patients ( 15 female \& 6 male) with carcinoma were detected (papillary 15, follicular 3, anaplastic 2, lymphoma 1). In 98 patients with Multinodular goiter 10 patients ( 7 females \& 3 male ) were proved carcinoma on histopathological examination, out of which 5 patients have papillary, 3 have follicular, 1 have anaplastic \& 1 have lymphoma on report. Maximum patients with carcinoma belong to $41-50$ years age group with Mean age of 45.2 years. Among these 10 patients who were diagnosed as carcinoma 6 patients were male and 4 were female.

\begin{tabular}{|c|c|c|}
\hline Type of thyroid carcinoma & No. of cases & Percentage \\
\hline Papillary carcinoma & 15 & $71.4 \%$ \\
\hline Follicular carcinoma & 3 & $14.2 \%$ \\
\hline Anaplastic carcinoma & 2 & $09.5 \%$ \\
\hline Lymphoma & 1 & $04.7 \%$ \\
\hline Total carcinoma/Total cases & $21 / 141$ & $14.9 \%$ \\
\hline
\end{tabular}

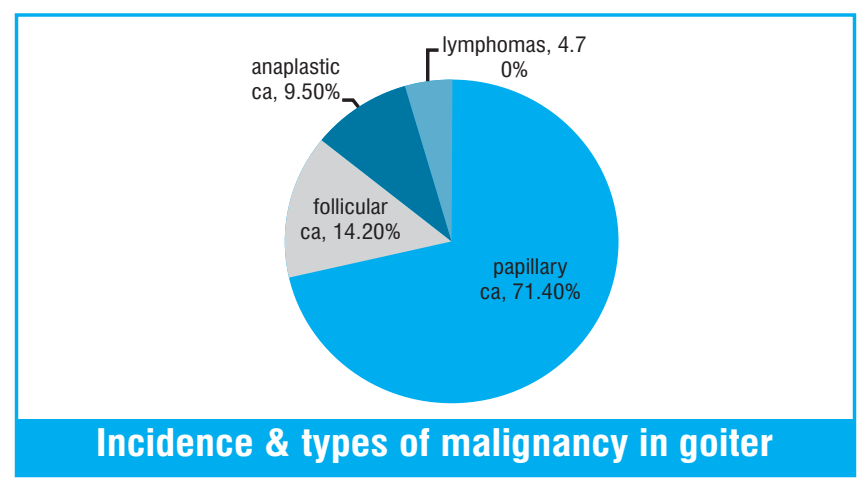

\begin{tabular}{|c|c|c|}
\hline Type of thyroid carcinoma & No. of cases & Percentage \\
\hline Papillary carcinoma & 5 & $50 \%$ \\
\hline Follicular carcinoma & 3 & $30 \%$ \\
\hline Anaplastic carcinoma & 1 & $10 \%$ \\
\hline Lymphoma & 1 & $10 \%$ \\
\hline Ca in MNG/Total MNG & $10 / 98$ & $10 \%$ \\
\hline
\end{tabular}

Table-Il. Carcinoma cases in patients operated for Multinodular goiters.

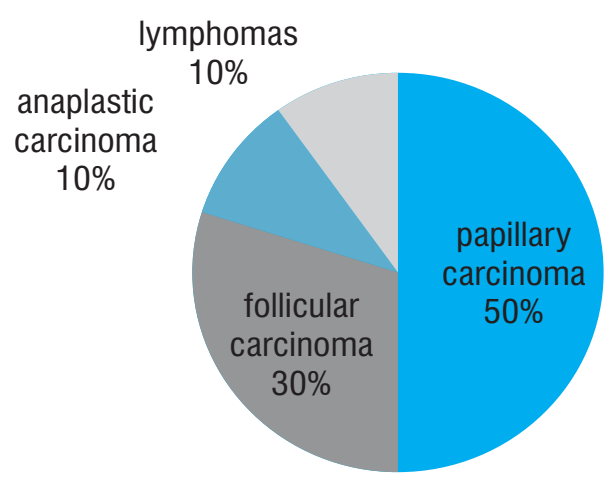

Incidence \& type of thyroid malignancy in MNG

\begin{tabular}{|c|l|}
\hline Age(years) & Type of carcinoma \\
\hline 45 & Papillary carcinoma \\
\hline 54 & Anaplastic carcinoma \\
\hline 41 & Papillary carcinoma \\
\hline 38 & Papillary carcinoma \\
\hline 42 & Follicular carcinoma \\
\hline 48 & Follicular carcinoma \\
\hline 34 & Lymphoma \\
\hline 47 & Papillary carcinoma \\
\hline 58 & Follicular carcinoma \\
\hline 45 & Papillary carcinoma \\
\hline
\end{tabular}

Table-III. Age of patients with MNG, in which carcinoma detected.

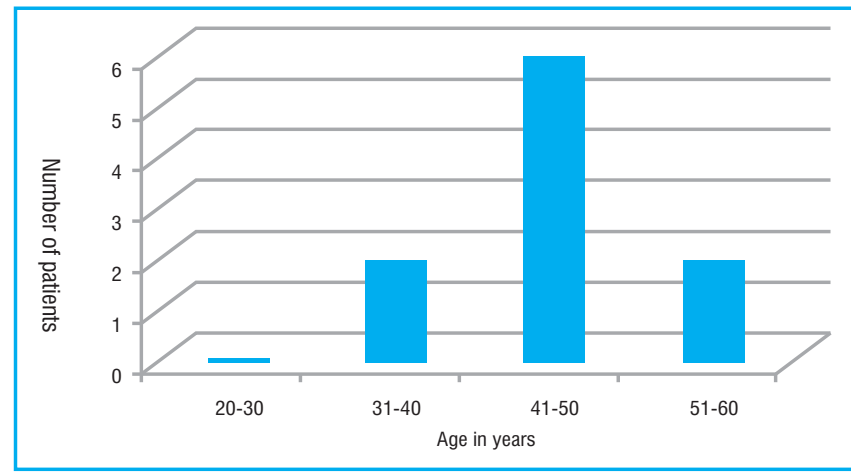

\section{DISCUSSION}

In Pakistan thyroid cancer is responsible for $1.2 \%$ cases of all malignant tumors. Thyroid carcinoma (TC) is a relatively rare tumor, but it represents the most 
frequent form of cancer of the endocrine glands ${ }^{2}$. A personal history of radiation to the neck, detection of calcifications by ultrasound or by neck X-rays, and a family history of thyroid diseases should be considered clinical risk factors for malignancy in multinodular goiter ${ }^{8}$. The female to male ratio in this part of the world is noted to be between 2.5 to $4: 1$, which is comparable to international data ${ }^{9,10}$. The overall incidence of malignancy in this study was $14.9 \%$ comparable to $14.3 \%$ another study done in Karachi Pakistan, whereas in USA it was $5.8 \%$, in Libya $9.7 \%$ and in South Africa $5.4 \%$. The studies from Riyadh reported a strikingly high incidence of thyroid malignancy ranging from $21 \%$ to $29 \%{ }^{11}$. In the present study, papillary carcinoma was more frequent $71.4 \%$ than the follicular variant which is in accordance with the published figures ${ }^{12,13}$. Previous reports from this region show papillary thyroid cancer to constitute 57 to $89 \%$ of all thyroid malignancies ${ }^{14,15}$. Another 2 studies done in India \& Pakistan revealed that reported incidence of papillary thyroid cancer in MNG is about $60 \%$ while in our study it is $50 \%$ which is almost same followed by follicular and then other types of malignancies $^{16,17}$.

\section{Copyright@ 08 Apr, 2013.}

\section{REFERENCES}

1. Grodski S, Brown T, Sidhu S, Gill A, Robinson B, Learoyd $D$,et al. Increasing incidence of thyroid cancer is due to increased pathologic detection. Surgery. 2008 Dec;144(6):1038-43; discussion 1043.

2. Gandolfi PP, Frisina A, Raffa M, Renda F, Rocchetti O, Ruggeri $\mathrm{C}$, et al. The incidence of Thyroid Carcinoma in Multinodular Goiter: retrospective analysis. Acta bio medica ateneo parmense 2004; 75; 114-117.

3. Giuffrida D, Gharib H. Controversies in the management of cold, hot and occult thyroid nodules. Am J Med 1995; 99:642-50.

4. Franklyn JA, Daykin J, Young J, et al. Fine needle aspiration cytology in diffuse multinodular goiter compared to solitary thyroid nodules. BMJ 1993; $307: 240$.
5. Rahman GA, Abdulkadir AY, Olatoke SA, Yusuf IF, Braimoh KT. Unusual cutaneous metastatic follicular thyroid carcinoma. J Surg Tech Case Report 2010; 2:35-8.

6. Abu-Eshy SA, Khan AR, Khan GM, al-Humaidi MA, alShehri MY, Malatani TS. Thyroid malignancy in multinodular goitre and solitary nodule. J R Coll Surg Edinb. 1995 0ct; 40(5):310-2.

7. Tollin SR, Mery GM, Jelveh N, Fallon EF, Mikhail M, Blumenfeld W, et al. The use of fine-needle aspiration biopsy under ultrasound guidance to assess the risk of malignancy in patients with a multinodular goiter. Thyroid. Mar.2000; 10(3):235-41.

8. Botrugno I, Lovisetto F, Cobianchi L, Zonta S, Klersy C, Vailati $A$, et al. Incidental carcinoma in multinodular goiter: risk factors. The American surgeon. Nov. 2011; 77(11):1553-8.

9. Zuberi LM, Yawar A, Islam N, Jabbar A. Clinical Presentation of Thyroid Cancer Patients in Pakistan AKUH Experience. J Pak Med Assoc 1999; 49:131-3.

10. Al-Salamah SM, Khalid K, Bismar HA. Incidence of differentiated cancer in nodular goiter. Saudi Med J. 2002 Aug; 23(8):947-52.

11. Hussain N, Anwar M, Nadia N, Ali Z. Pattern of surgically treated thyroid disease in Karachi. Biomedica. Jul. - Dec. 2004; 20: 18-20.

12. Kumar V, Abbas AK, Fausto N. Robbins and Cotran. Pathologic basis of diseases. 7th ed. Philadelphia, W. B. Saunders: 2004: 1178.

13. Parvez M, Malik AM, Anwar A. Solitary thyroid nodule, Incidence of thyroid cancers. Pak J Path. Dec 2001, 12(2): 25-9.

14. Shah SH, Muzaffar S, Soomro IN, et al. Morphological patterns and frequency of thyroid tumors. J Pak Med Assoc 1999; 49:131-3.

15. Mulaudi TV, Ramdial PK, Madiba TE, et al. Thyroid carcinoma at King Edward VIII Hospital, Durban, South Africa. East Africa Med J 2001; 78:252-5.

16. Najum ul Haq R, Ali Khan B, Ahmed Chaudhry I. Prevalence of malignancy in goitre-a review of 718 thyroidectomies. J Ayub Med Coll Abbottabad 2009; 


$$
21(4): 134-6 .
$$

17. Hanumanthappa MB, Gopinathan S, Suvarna R, Rai $G$, Shetty $G$, Shetty $A$, et al. The Incidence of
Malignancy in Multi-nodular Goitre: A Prospective Study at a Tertiary Academic Centre. Journal of Clinical and Diagnostic Research. Apr.2012; 6(2): 267-270.
AUTHOR(S):

1. DR. KASHIF NADEEM

FCPS Surgery

Senior Registrar Surgical Unit-I

Sheikh Zayed Medical College/Hospital

Rahim Yar Khan

2. DR. NAVEED AKHTAR

3. DR. JAVED MIRDAD TARAR

\section{Correspondence Address:}

\section{Dr. Kashif Nadeem}

FCPS Surgery

Senior Registrar Surgical Unit-I

Sheikh Zayed Medical College/Hospital

Rahim Yar Khan

dr.kashif099@yahoo.com
Article received on: 12/02/2013 Accepted for Publication: 08/04/2013 Received after proof reading: 21/05/2013

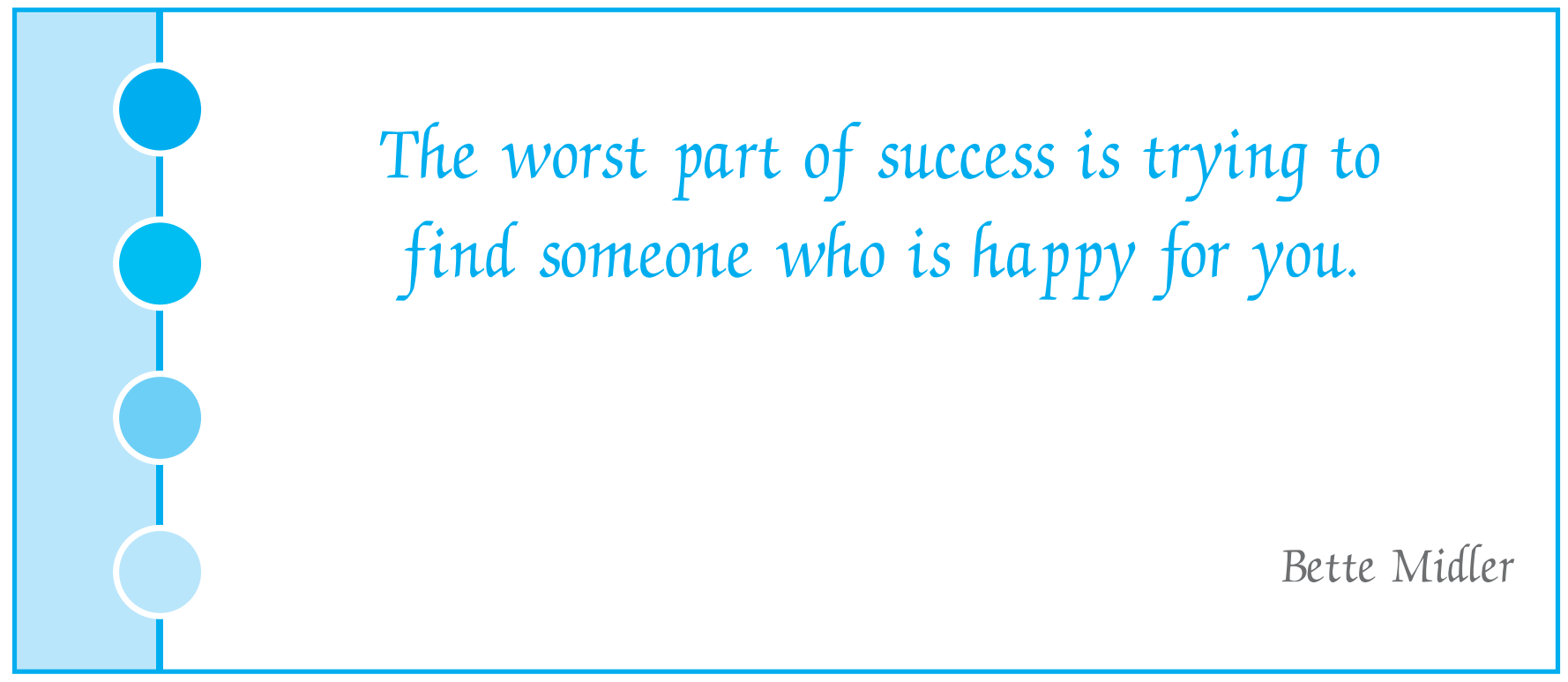

